\title{
Atlas of Indonesian Batik: Javanese Batik
}

\author{
Candra Sari Djati Kartika ${ }^{\mathrm{a}}$ *, Zulfa Nur'aini 'Afifah ${ }^{\mathrm{b}}$, Adriati Annisa Utami ${ }^{\text {a }}$ \\ ${ }^{a}$ Faculty of Geography, Universitas Gadjah Mada, candrakartika@ ugm.ac.id, Faculty of Geography, Universitas Gadjah Mada, \\ adriati.annisa.u@mail.ugm.ac.id \\ ${ }^{b}$ Faculty of Geography, Universitas Gadjah Mada, zulfa.nuraini@mail.ugm.ac.id \\ * Corresponding author
}

\begin{abstract}
Thematic atlas could be developed using storytelling concept to convey information about a certain theme to the targeted users. This initial research aims to develop Atlas of Indonesian Batik that was made not only to collect maps that contain information about the distribution of Indonesian Batik, but also intended to provide information about history, the development of its motives and procedures for making it to educate students and society about Indonesian traditions and as a national identity. Indonesian Batik is a cultural heritage that represents the characteristic of Indonesia which also depict the long history and acculturation of various culture in Indonesia. Indonesian Batik is also appointed as a Masterpiece of Oral and Intangible Heritage of Humanity in 2016 by UNESCO. Each region in Indonesia has a variety of batik patterns that shows the characteristics of each region which can be used to introduce the area, and for this research we mostly focused in Javanese Batik as this type of batik is mostly common in Indonesia. All of the information from the literature review, interview with experts and visit to the batik industry were compiled and visualized using text, images and maps into printed atlas pages that ordered from general knowledge to thematic information to make it easier to read and attract the interest of map readers, especially students as an effort to preserve Indonesian culture.
\end{abstract}

Keywords: Thematic Atlas, Storytelling, Batik, Indonesia

\section{Introduction}

Thematic atlas is an atlas that shows a particular theme which can be selected from a variety of themes ranging from physical geography to social themes, such as cultural studies. Current technological developments influence the development of thematic atlases. The increasing number of information, user cognitive abilities and needs lead to developments in designing an effective and efficient thematic atlas as atlas currently not only used as a visual representation of spatial phenomenon but also develop as a media for storytelling. Storytelling atlas receive more user's attention (Sun et al, 2015), as this atlas organized in certain orders to make it into a coherent series of events to tell story about the events. Integration of maps, pictures, text and media were used to transfer the information using narrative concept to build this atlas.

In Indonesia, thematic atlas has begun to develop. The National Geospatial Information Agency (BIG) has published not only national atlases but also several thematic atlases such as ethnic atlas and cultural atlas: temple edition ${ }^{1}$. In addition, BIG also provides atlases for certain users such as educational atlas and tactile atlas. Another thematic atlas was compiled by the Ministry of Forestry that called Indonesian Wood Atlas which provide comprehensive information about various species of wood and timber production in Indonesia.

Most of the thematic atlases in Indonesia only emphasized about the distribution of the phenomena and explanation about the data. Themes that were chosen also mostly about social economy or resources that only use maps or atlases as a visual representation of the data. Atlas as a story telling media with narrative concept is still unfamiliar, therefore this research is conducted to give a new perception about atlas.

Batik is chosen as our theme as batik is Indonesia's national cultural heritage which characterize Indonesian culture. Therefore, it requires conservation measures to ensure the sustainable and the uniqueness of batik which distinguish Indonesian culture. Batik preservation can not only be done by using batik in daily life or establishing a national batik day, but the most important thing is documenting the batik into a media that is able to store not only batik motifs in Indonesia but also history, distribution and all of information about batik in Indonesia. Visualizing this information in the form of thematic atlas is one of the most suitable methods to preserve batik culture. Using narrative concept, this thematic atlas could convey information in lightheartedness that could attract the targeted users,

\footnotetext{
1 BIG: "Atlas" http://www.big.go.id/atlas/ retrieved: 6 April 2019
} 
young audience, as they are the successor of our culture. This atlas could also be used as national identity as this atlas documented our culture which distinguish our nation.

\section{ATLAS DESIGN AND TECHNICAL WORK}

Before producing thematic atlas, first we determine the intent of the atlas and the group of potential users to build a cartographic project (Vozenilek, 2015). The aims of producing this Atlas are to collect maps that contain information about the distribution of Indonesian Batik and to provide information about history, the development of its motives and procedures for making it to educate students and society about batik. From these purposes we develop a cartographic project which specify the key cartographic information (batik distribution), atlas design and map layout, draft of atlas content which included the history and procedures of batik making and data processing.

\subsection{Cartographic Information}

The key cartographic information that we choose is batik's motif distribution. Map is used to convey this information, as map could visualize the spatial distribution of the theme to build a background knowledge to understand the development of the batik's motif. As this atlas is prepared for users without prior knowledge about maps or cartographic representation, the design of the map is simplified to make it easier to understand.

\subsection{Atlas Design and Map Layout}

Preparing for designing thematic atlas included setting basic rules and procedures (Cajthaml et al, 2013), in particular choice of cartographic representation, projections, symbols of the map, media used on the map and map layout. As stated, maps were used as the cartographic representation. All maps were produced using ESRI ArcGIS Desktop 10 as the dataset was stored in shapefile type and ArcGIS also provide tools to create high quality map. Transverse Mercator projections was used for all of the map. As this atlas is more focused on the thematic information, we try to make map symbol as simple as possible to make it easier to read for the reader such as using color for areas, various line symbols for borders and point symbol to represent the capital city or city of the area where the batik's motif is known.

As we are using storytelling concept, we combine maps with text and images to give a detail information about batik's motif in narrative ways. Due to the differences in the length of the area and the number of information, it is impossible to use a single map structure and layout resulting variety of layouts are used in this atlas. For the layout for each section, the main title should be put on the top of the page to give clear context about the information on the page to the reader. To differentiate the title with other text, we are using different font type, font size and color. As batik in Java mostly used brown color, we are using brown for the title for each section.

For pages that contains thematic information, the pages will adopt the layout from Atlas Budaya Edisi Candi (2015) which divide the page into two columns for text element while maps and images could be placed in one of the columns or following the page width.

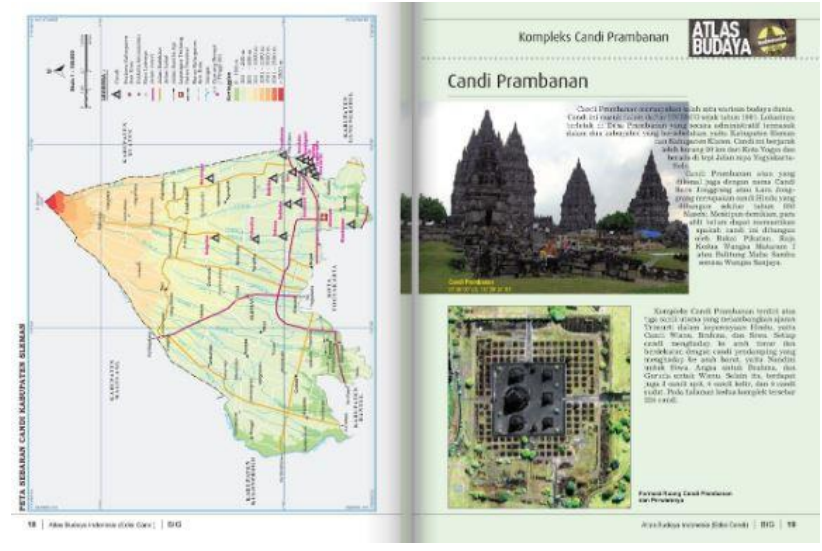

Figure 1. Pages structure in Culture Atlas of Indonesia: Temple Edition (C) BIG Copyright 2016

\subsection{Atlas Content}

As mentioned before, this atlas is using narrative concept to convey information to the users. Therefore, the content of this atlas is not only consisting of maps but also pictures, photos and text to give a better understanding about the information and to attract reader's interest as this atlas intended to general public so that not all of the readers familiar and have interest with map. The content of this atlas collected from various sources such as literature review, visiting batik industry and interview with expert. Cooperation with experts in batik as thematicians is important to maintain the quality and validity of the information as we are also not too familiar with the theme. As atlas content is one of the main prerequisites for thematic atlas making and we are using narrative concept, the information must be selected carefuly for the atlas content to make it informative yet easily understand and still enjoyable to read. All of the content will be prepared using the rules and procedures that already set before.

\subsection{Technical Work}

Based on the proposed atlas design, the technical work which modified from technical routes proposed by Sun et al (2015) is shown in the Figure 2.

\begin{tabular}{|c|c|c|}
\hline & \multicolumn{2}{|c|}{ Technical Work } \\
\hline Narrative content & \multirow{2}{*}{ Narrative theme } & \multirow{2}{*}{ Content Arrangement } \\
\hline Atlas design rules & & \\
\hline Data processing & $\begin{array}{l}\text { Map processing: } \\
\text { Designing map elements } \\
\text { Producing map elements }\end{array}$ & $\begin{array}{l}\text { Other element: } \\
\text { Information selection } \\
\text { Elements arrangement and adjustment }\end{array}$ \\
\hline Prototype design & \multicolumn{2}{|c|}{$\begin{array}{l}\text { Atlas layout design } \\
\text { Atlas stucture and relationships }\end{array}$} \\
\hline
\end{tabular}

Figure 2. Technical work of atlas batik using narrative concept

\section{PROTOTYPE DESIGN}

All of the information and the data that already obtained and processed in the preparation work are used to build the prototype of the atlas. Using the rules and procedures that appointed before, the maps were organized gradually from basic information to the thematic information about batik's motif from each region. 


\subsection{Relationships of the maps}

Using narrative concept, we must determine the plotline to structure the atlas. For the plotline we are using batik history, batik distribution in Java Island and batik's motif for each region. The atlas will be started with the history of batik including the procedure of batik making to give a background knowledge about the theme for the reader. The distribution of batik in Java Island and some fact about batik industry will be introduce in the next part. This part will be the bridge to deliver the next part which is the batik's motif for each region that mentioned in this part. For each region, the information consists of the batik's motif, the history and the picture of the batik's motif. And for the last part, we introduced some of batik and traditional fabrics from other regions of Indonesia as an outset for the next volume of the atlas.

\subsection{Visualization}

To emphasize the theme for the atlas, we are using batik's motif in the cover of the atlas and as a background for some pages (foreword, table of content, etc.). For other pages, we are using white color as background to give contrast with the content of atlas which majority consist of text in black color, pictures and images, graph and maps. We include a table of content to depict the relationship between each part which shows the transition from general knowledge about batik to specific information about batik's motif for each region.

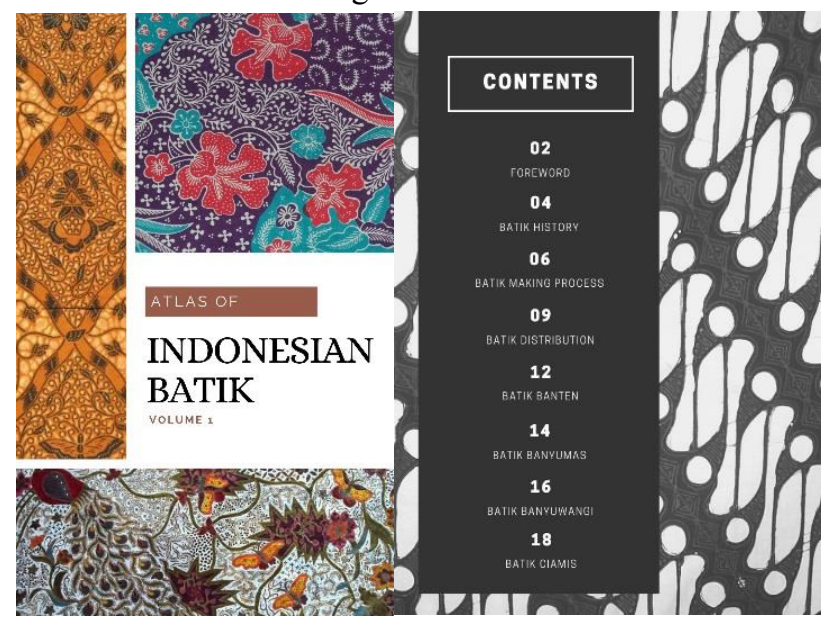

Figure 3. Atlas cover and table of contents that using batik's motif as one of the elements

The main map that show the distribution of batik in Java Island is visualized using color to distinguish the region which has batik and the region which not. Same as the title for each page section, we are using light yellow to represents the region which does not produce batik and light brown to represent the region which produce batik and we divided Java Island based on administrative border for district. While for the map that show for each region, we only using light brown color to highlight the region and point symbol to represent the capital city for each region. We also use black color text as toponym to give clear identification for each region.
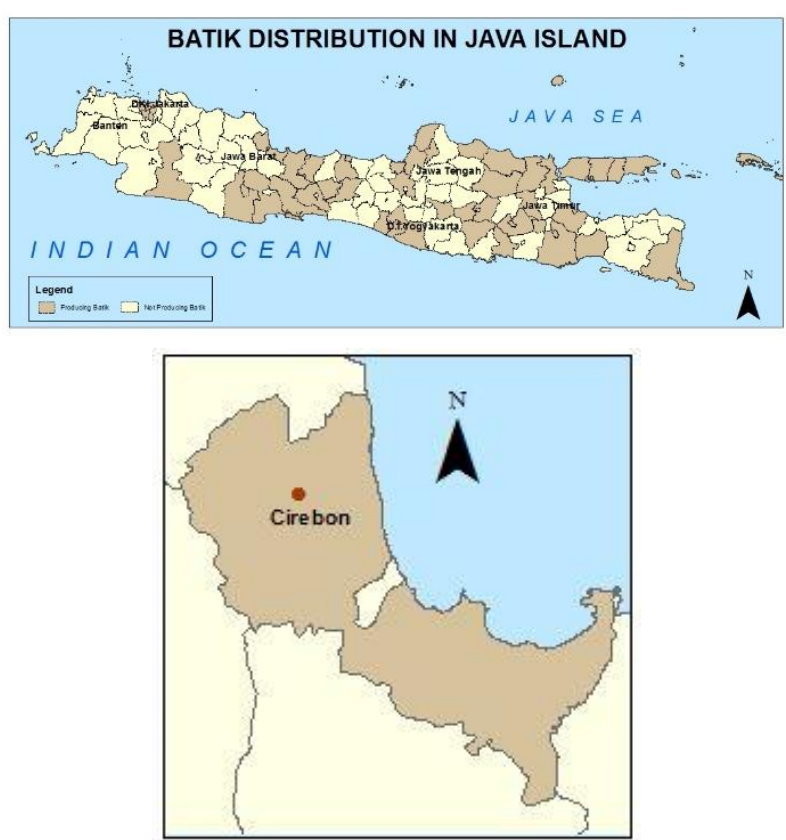

Figure 4. Main map that show batik distribution in Java Island and map for showing each region which produce batik

The pages that contains thematic information are having different structure and layout because the difference number of information, pictures or area length. However, there are some basic rules that should be kept such as the title should be on the top of the pages with brown color, divide page into two columns for text element, used different size and color for heading to differentiate with the text, the content should be full of information but not too much.

\section{BATIK CIREBON}

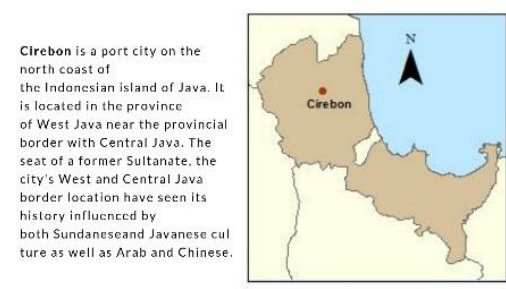

Batik Cirebon memiliki 2 kategori desain, yaitu desain keraton dan juga motif pesisiran. Desain keraton diambil dari ornamen-ornamen keraton dan warnanya cenderung warna sogan dan babar mas. Sementara desain pesisiran mengandung laut dan memiliki warna yang agak terang.
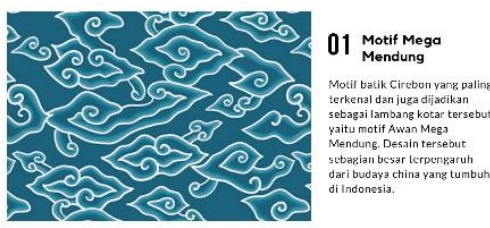

Figure 5. Example of page with thematic information

This prototype design is printed into A4 size paper to reduce the production cost so that this atlas could be available for everyone. This size also feels more friendlier for amateur reader than the bigger size as our new 
generation now are lacking interest in reading printed books.

\subsection{Conclusion}

Thematic atlas mostly compiled to visualize information for certain targeted users with prior knowledge about the theme. However, using narrative concept for the atlas will broaden the targeted users and will give a different experience as the atlas will be deliver information in more interesting way just like a story book. The atlas will be structured from general knowledge to thematic information to give a better flow and to make it easier to understand.

In this study, we proposed a conceptual atlas design using narrative concept to deliver information about batik generally to public and especially to our new generation as an effort to preserve our culture. This atlas combines maps, images, text and graphics to visualize the information that could also be used as national document that store our history and culture. Yet, because of time restrictions evaluation for the result of this study could not be done. Therefore, for further study we will try to evaluate the readability and effectivity of the design proposed in this study to give improvement so that this atlas could fulfil its aims.

\subsection{Acknowledgements}

We would like to give our gratitude to Universitas Gadjah Mada for the support to make this research possible.

\section{References}

Badan Informasi Geospasial. (2015). Atlas Budaya Edisi Candi: Meneropong Candi dari Aspek Geospasial Tahun 2015. Cibinong: Badan Informasi Geospasial.

Cajtaml, J., Janata, T., Seemann, P., \& Zimová, R. (2013). Designing Maps for a New Thematic Atlas of the Czech History. Proceedings of 26th International Cartographic Conference, August 2530, 2013, Dresden, Germany.

Sun, F., Tang, X., Ye, T., \& Zhu, F. (2015). Thematic Atlas Information Expansion Design: A Storytelling Concept Under Web Wnvironment. 23rd International Conference on Geoinformatics, June 19-21, 2015, Wuhan, China. https://doi.org/10.1109/GEOINFORMATICS.2015. 7378701

Vozenilek, V. (2015). Aspects of the Thematic Atlas Compilation. In: Brus J., Vondrakova A., Vozenilek V. (eds) Modern Trends in Cartography. Lecture Notes in Geoinformation and Cartography. Springer, Cham. https://doi.org/10.1007/978-3-319-07926-4_1 